\title{
Discrete-time Sensorless Control Using new BS_SM Controller structure and VM_SC MRAS Adaptive Speed Observer for The propulsion system of Ship
}

\author{
NGOC THUY PHAM \\ Industrial University of Ho Chi Minh City \\ Dept. of Electrical Engineering Technology \\ VIETNAM
}

\begin{abstract}
In this paper, a (BS_SM) new Backstepping_Sliding mode controll structure combined with a (VM_SC_MRAS) improved stator current MRAS based on adaptive speed observer using neuron network and sliding mode are proposed to sensorless vector control for The propulsion system of Ship. The design of the controller is based on new BS and SM sructure to improve its performance and robustness. VM_SC_MRAS improved adaptive speed observer is proposed to estimate the speed of propeller. The combination of BS-SM controller with VM_SC_MRAS adaptive speed observer can compensate for the uncertainties caused by the machine parameter variations, measurement errors, and load disturbances, improving dynamic performance and enhancing the robustness of the SPIM drive system, perfect tuning of the speed reference values, fast response of the motor current and torque, high accuracy of speed regulation. The simulation results lead to the conclusion that the proposed system for the propulsion system of ship is feasible. The simulation results on a test ship propelled showed that the proposed control approach operates satisfactorily.
\end{abstract}

Key-Words: - Backstepping control, SM control, six phase induction motor drives, FOC vector control, the propulsion system of Ship.

Received: May 5, 2020. Revised: October 26, 2020. Accepted: November 14, 2020. Published: December 1, 2020

\section{Introduction}

In recent years, due to the effect of the greenhouse effect and the lack of fossil energy, the increasing price of gasoline, etc. are challenges for sustainable development of transport. For these reasons, electric propulsion systems gradually have researched to replace in main propulsion systems as well as auxiliary systems in ships in particular and another means of transportation in general such as electric vehicles, aeronautics, etc. [142-154] such as a solution for energy and environmental issues. A lot of attention is paid to the development of electric propulsion systems in marine vessels (fishing vessels) such as ssysteize, weight, noise, vibration, precision control, quality and performance the drive systems are the main interested aspects of any marine propulsion system, and they are especially important for fishing vessels. In ship pushing applications, multi-phase motor drives are becoming more and more popular than traditional three-phase machines [155-156], due to their outstanding advantages suitable for application in systems. The propulsion systems such as fault tolerance [159161], high torque [155], low torque [156], reduced vibration and noise $[157,158]$, etc. Among multiphase motors, asymmetric SPIM is one of the most popular types of multi-phase motors. However, the conventional FOC strategies using PI control cannot provide satisfactory quality for high performance drives. In order to overcome these, recently nonlinear control methods have been developed to replace PID controllers [8], [9]. The nonlinear techniques have been proposed for SPIM drive systems such as [10-17]: Regulatory linear control [10], slip model control theory (SM) [11], Backstepping control (BS) [12 ], Fuzzy Logic (FL) control [13] and neural network control (NN) [14], prediction control [15], passive control [16], Hamiltonia control [17],. v..v. Among the nonlinear control methods, BS receives a great deal of attention due to the systematic design and effective control of nonlinear responses [18]. The greatest advantage of this method is the flexibility, the ability to retain useful nonlinear elements and pursue good stability and tracking goals. However, detailed and accurate information about SPIM parameters is required when designing a traditional BS controllers. So it is difficult to use the independent BS control method to meet the requirements of high quality drive systems. In fact, BS method has been studied to combine with other control methods, such as combined with sliding mode control [19], neural network [20], fuzzy logic system ( FLS) [21] to get a effective control system. 
In this paper, the author proposes a combined control structure: BS controller is applied in external speed closed-loop control, SPIM model parameters are updated for controller to minimizing the effect of changing the parameters on the efficiency of the controller, the controller design based on BS technology has also been improved, adding the tracking error integration component to improve its sustainability. The SM control technique is proposed for internal loop current control to improve the quality of control and ensure the stability, accuracy speed response of the drive system, improve robustness against the sensitivity of changes in machine parameters, load disturbances.

The other side, the implementation of vector control techniques requires accurate information about the speed and rotor flux. The current, voltage and speed sensors are often used to provide speed information and estimate the rotor flux. However, the recent trend eliminate the mechanical sensors used to measure speed because they are sensitive, cause noise, increase cost, size, weight and reduce reliability [22]. There has been a lot of attention from researchers to reduce the number of sensors. In this paper, the authors has focused on the accurate rotor flux estimation, and estimated the speed and resistance values of $\mathrm{Rs}$ and $\mathrm{Rr}$ by the improved stator current based on reference model adaptive systemt (SC_MRAS) using neuron network to improve the performance of observer and controller for the high performance SPIM drives. In detail, in the proposed NN_SC_MRAS observer, the reference model uses the stator current components to free of pure integration problems and insensitive to motor parameter variations. In this SC_MRAS scheme are, first: Adaptive Model uses a two layer linear neural network, which is trained online by a linear LS algorithm, this algorithm requires the less computation effort and overcome some drawbacks, which cause by its inherent nonlinearity as in literature published before [19]. This significantly improves the performance of the proposed observer. Second: the adaptive model based on NN is implemented in the prediction mode. This improvement ensures the proposed observer operate better accuracy and stability. Third: the rotor flux, which is needed for the stator current estimation of the adaptive model, is identifier by the Voltage Model (VM) with the stator resistance value is estimated online to enhance the performance of the proposed NN_SC_MRAS observer, in addition, using VM will avoid the instability in the regenerating mode. In this proposed, rotor resistance value also has been estimated based on its variation proportional to that one of stator resistance, then the estimated resistance values were updated for the current observer to estimate the current exactly more. Finally, the modified Euler integration has been used in the adaptive model to solve the instability problems due to the discretization of the rotor equations of the machine enhance the performance of observer. The effectiveness of this proposed schemes is verified by simulation using MATLAB/ Simulink.

The paper is organized into five sections, in section 2, the basic theory of the model of the SPIM and the SPIM drive are presented. Section 3 introduces $\mathrm{BS}_{-}$SM controller, NN_ SC MRAS observer also is introducted in this part. Simulation and discuss are presented in Section 4. Finally, the concluding is provided in Section 5.

\section{Model of SPIM and electric propulsion system}

\subsection{Model of SPIM}

The drive system under study consists of an SPIM fed by a six-phase Voltage Source Inverter (VSI) and a DC link. A detailed scheme of the drive is provided in Fig.1. Problem Formulation

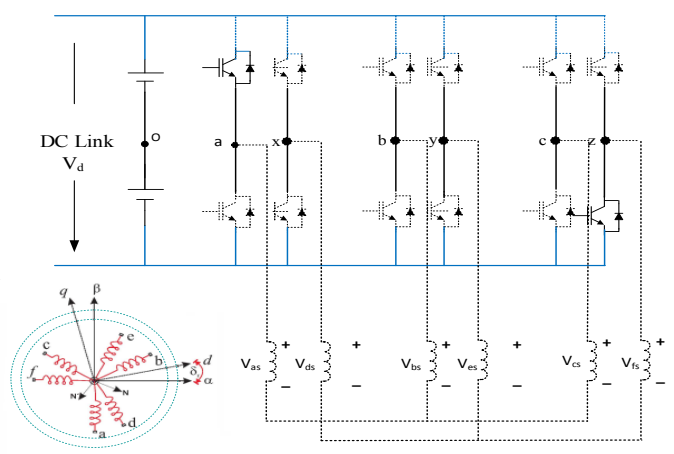

Figure. 1. A SPIM drive general diagram

By applying the Vector Space Decomposition (VSD) technique introduced in [32], the original sixdimensional space of the machine is transformed into three two-dimensional orthogonal subspaces in the stationary reference frame (D-Q), $(\mathrm{x}-\mathrm{y})$ and $(\mathrm{zl}$ $-\mathrm{z} 2$ ). This transformation is obtained by means of 6x6 transformation matrix (Eq.1). In order to develop SPIM model for control purposes, some basic assumptions should be made. Hence, the windings are assumed to be sinusoidally distributed, the magnetic saturation, the mutual leakage inductances, and the core losses are neglected. 


$$
T_{6}=\frac{1}{3}\left[\begin{array}{cccccc}
1 & -\frac{1}{2} & -\frac{1}{2} & \frac{\sqrt{3}}{2} & -\frac{\sqrt{3}}{2} & 0 \\
0 & \frac{\sqrt{3}}{2} & -\frac{\sqrt{3}}{2} & \frac{1}{2} & \frac{1}{2} & -1 \\
1 & -\frac{1}{2} & -\frac{1}{2} & -\frac{\sqrt{3}}{2} & \frac{\sqrt{3}}{2} & 0 \\
0 & -\frac{\sqrt{3}}{2} & \frac{\sqrt{3}}{2} & \frac{1}{2} & \frac{1}{2} & -1 \\
1 & 1 & 1 & 0 & 0 & 0 \\
0 & 0 & 0 & 1 & 1 & 1
\end{array} \mid\right.
$$

The electrical matrix equations in the stationary reference frame for the stator and the rotor may be written as

$$
\begin{aligned}
& {\left[V_{s}\right]=\left[R_{s}\right]\left[I_{s}\right]+p\left(\left[L_{s s}\right]\left[I_{s}\right]+\left[L_{s r}\right]\left[I_{r}\right]\right)} \\
& {[0]=\left[R_{r}\right]\left[I_{r}\right]+p\left(\left[L_{r r}\right]\left[I_{r}\right]+\left[L_{r s}\right]\left[I_{s}\right]\right)}
\end{aligned}
$$

where: $[\mathrm{V}],[\mathrm{I}],[\mathrm{R}],[\mathrm{L}]$ and $[\mathrm{Lm}]$ are voltage, current, resistant, self and mutual inductance vectors,

respectively. $\mathrm{P}$ is differential operator. Subscript $\mathrm{r}$ and $\mathrm{s}$ related to the rotor and stator resistance respectively. Since the rotor is squirrel cage, $[\mathrm{Vr}]$ is equal to zero. The electromechanical energy conversion only takes place in the DQ subsystem:

$$
T_{2}=\left[\begin{array}{cc}
\cos \left(\delta_{r}\right) & -\sin \left(\delta_{r}\right) \\
\sin \left(\delta_{r}\right) & \cos \left(\delta_{r}\right)
\end{array}\right]
$$

where $\delta r$ is the rotor angular position referred to the stator as shown in Fig. 1.

As these equations implies, the electromechanical conversion, only takes place in the D-Q subspace and the other subspaces just produce losses. Therefore, the control is based on determining the applied voltage in the $\alpha \beta$ reference frame. With this transformation, the 6PIM control technique is similar to the classical three phase IM FOC. The control for the motor in the stationary reference frame is difficult, even for a three phase IM, so the transformation of SPIM model in a dq rotating reference frame to obtain currents with $\mathrm{dc}$ components [23] của 1 is necessary, a transformation matrix must be used to represent the stationary reference fame $(\alpha-\beta)$ in the dynamic reference $(d-q)$. This matrix is given:

$\left.\left[\begin{array}{c}V_{s \alpha} \\ V_{s \beta} \\ 0 \\ 0\end{array}\right]=\left[\begin{array}{cccc}R_{s}+P L_{s} & 0 & P L_{m} & 0 \\ 0 & R_{s}+P L_{s} & 0 & P L_{m} \\ P L_{m} & \omega_{r} L_{m} & R_{r}+P L_{r} & \omega_{r} L_{r} \\ -\omega_{r} L_{m} & P L_{m} & -\omega_{r} L_{m} & R_{r}+P L_{r}\end{array}\right] \| \begin{array}{c}I_{s \alpha} \\ I_{s \beta} \\ I_{r \alpha} \\ I_{r \beta}\end{array}\right]$

\subsection{Model of electric propulsion system}

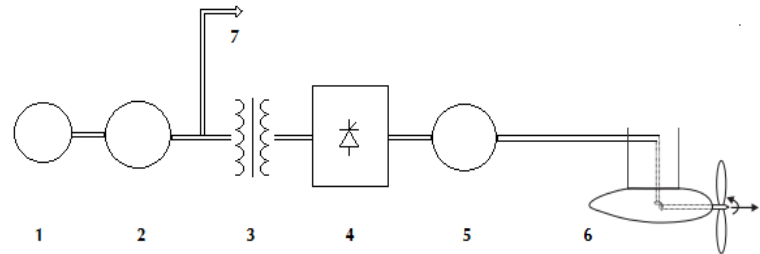

Fig. 2 The diagram of proposed drive in the ship

1. Primary engine (Diesel, electrical or Gas engine, etc.)

2. Synchronous generator

3. Power transformer

4. Six-phase drive system

5. Motor (Multi_phase induction motor)

6. Propeller

7. Other loading needs (pumps, winches, lighting, etc.)

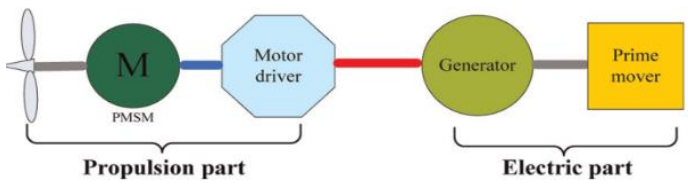

Fig. 3. Ship propulsion system using SPIM [24]

The principle of the FOC is to align the $d$ axis of the rotating frame (d-q) with the desired flux. Therefore, the flux will be controlled by the direct component of the stator current (isd) and the torque by the quadratic component (isq). In this case we obtain: $\psi_{r q}=0 ; \psi_{r d}=\psi_{r d}$. Using Eqs. The equation of the SPIM drive in the rotary reference coordinates can be written as follows:

$$
\left\{\begin{array}{l}
L_{s} \frac{d i_{s d}}{d t}=-a i_{s d}+L_{s} \omega_{e} i_{s q}+b R_{r} \psi_{r d}+c u_{s d} \\
L_{s} \frac{d i_{s q}}{d t}=-a i_{s q}+L_{s} \omega_{e} i_{s d}+b_{r} \omega_{e} \psi_{r d}+c u_{s q} \\
\frac{d \omega_{r}}{d t}=\frac{3}{2} P \frac{\delta \sigma L_{s}}{J}\left(\psi_{r d} i_{s q}\right)-\frac{T_{L}}{J}-B \omega_{r} \\
\frac{d \psi_{r d}}{d t}=\frac{L_{m}}{\tau_{r}} i_{s d}-\frac{1}{\tau_{r}} \psi_{r d}
\end{array}\right.
$$

where

$$
\begin{aligned}
& \sigma=1-\frac{L_{m}^{2}}{L_{s} L_{r}} ; \delta=\frac{L_{m}}{\sigma L_{s} L_{r}} ; a=\frac{L_{m}^{2} R_{r}+L_{r}^{2} R_{s}}{\sigma L_{r}^{2}} ; \\
& b=\frac{L_{m}^{2} R_{r}}{\sigma L_{r}^{2}} ; c=\frac{1}{\sigma} ; \tau_{r}=\frac{L_{r}}{R_{r}}
\end{aligned}
$$

The electromagnetic torque and the slip frequency can be expressed in dq reference frame:

$$
T_{e}=\frac{3}{2} n_{p} \frac{L_{m}}{L_{r}} \psi_{r d} i_{s q}
$$




$$
\omega_{s l}=\frac{L_{m}}{L_{r}} \psi_{r d} i_{s q}
$$

We also have:

$$
T_{e}=T_{L}+B \omega_{r}+J \frac{d \omega_{r}}{d t}
$$

To propel the ship, SPIM supplies torque directly to the propeller. Then the propeller creates thrust to drive the ship. Therefore, SPIM, propeller and hull together form the propulsion system in the electric propulsion system ship. SPIM's load is the hull resistance that the propeller thrust needs to overcome. The hydrodynamic properties of the hull propeller can be expressed as in [24]

$$
\begin{aligned}
& k_{1} m \frac{d v}{d t}=P\left(1-T_{d}\right)-R_{f} \\
& P=k_{p} \rho n^{2} D_{p}^{4} \\
& R_{f}=k_{2} v^{2}
\end{aligned}
$$

where $\mathrm{k} 1$ is the water coefficient, $\mathrm{m}$ is the hull weight, vs is the speed of the ship, $\mathrm{P}$ is the propeller thrust, $\mathrm{Td}$ is the coefficient of thrust reduction, $\mathrm{Rf}$ is the hull resistance, $\mathrm{k} 2$ is the power factor In the hull, $\rho$ is the sea density, $\mathrm{Dp}$ is the diameter of the propeller, $\mathrm{kp}$ is the thrust coefficient and $\mathrm{n}$ is the propeller rotation speed. The load torque of propeller is:

$T_{p}=k_{m} \rho n^{2} D_{p}^{5} \square k n^{2}$

where, $\mathrm{km}$ is the torque factor. Tp load torque is equal to TL (SPIM external load), $\mathrm{k}$ is the composite coefficient of hull resistance.

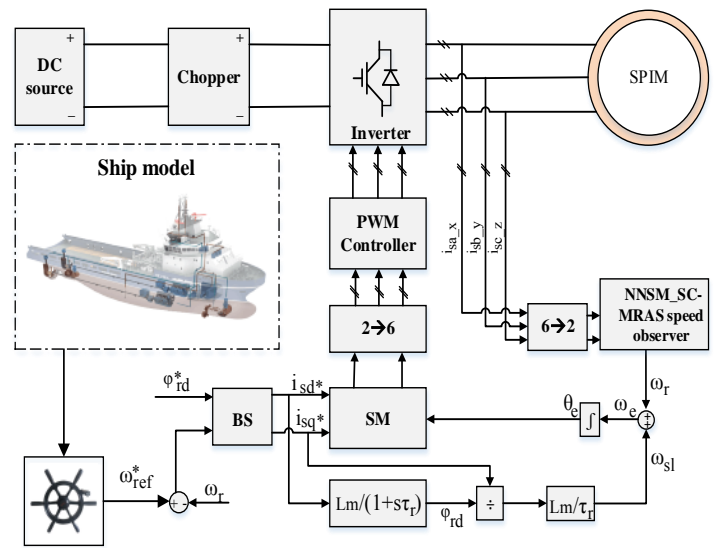

Fig. 4 FOC drive using BS_PCH combined

\section{The BS_SM controller combinates NN_ SC MRAS observer for sensorless vector control of SPIM drives}

\subsection{The proposed BS controller for outer speed control and rotor flux loops}

The purpose of this study is to design a simple control law but for high dynamic and establishing performance, eliminating load disturbance and effect of motor parameter variations. The influence from the change of parameters and the load disturbance can be significantly reduced by adding a tracking error integration when designing the BS speed controller and updating the rotor resistance for BS control. BS techniques are a systematic and recursive method for synthesizing nonlinear control rules. The stability and performance of the subsystems is studied by Lyapunov theory. Therefore, at each step of the design, a virtual command is created to ensure the convergence of subsystems.

$$
\begin{aligned}
& \varepsilon_{\omega}=\left(\omega_{r}^{*}-\omega_{r}\right)+k_{\omega}^{\prime} \int_{0}^{t}\left(\omega_{r}^{*}-\omega_{r}\right) d t \\
& \varepsilon_{\psi}=\left(\psi_{r d}^{*}-\psi_{r d}\right)+k_{\psi}^{\prime} \int_{0}^{t}\left(\psi_{r d}^{*}-\psi_{r d}\right) d t
\end{aligned}
$$

The error dynamical equations are

$$
\begin{aligned}
& \dot{\varepsilon}_{\omega}=\dot{\omega}_{r}^{*}-\frac{3}{2} P \frac{\delta \sigma L_{s}}{J} \psi_{r d} i_{s q}+\frac{T_{l}}{J}+B \omega_{r}+k_{\omega}^{\prime}\left(\omega_{r}^{*}-\omega_{r}\right) \\
& \dot{\varepsilon}_{\psi}=\dot{\psi}_{r d}^{*}+\frac{L_{m}}{\tau_{r}} i_{s d}+\frac{1}{\tau_{r}} \psi_{r d}+k_{\psi}^{\prime}\left(\psi_{r d}^{*}-\psi_{r d}\right)
\end{aligned}
$$

To obtain the virtual controller of speed and rotor flux loop, the following Lyapunov function candidate is considered:

$$
V_{(\omega, \psi)}=\frac{1}{2}\left(\varepsilon_{\omega}^{2}+\varepsilon_{\psi}^{2}\right)
$$

Differentiating $V$ :

$$
\begin{aligned}
& \frac{d V_{(\omega, \psi)}}{d t}=\varepsilon_{\omega} \frac{d \varepsilon_{\omega}}{d t}+\varepsilon_{\psi} \frac{d \varepsilon_{\psi}}{d t} \\
& =\varepsilon_{\omega}\left[\frac{d \omega_{r}^{*}}{d t}-k_{t} \psi_{r d} i_{s q}^{*}+\frac{T_{l}}{J}+B \omega_{r}+k_{\omega}^{\prime}\left(\omega_{r}^{*}-\omega_{r}\right)\right] \\
& +\varepsilon_{\psi}\left[\frac{d \psi_{r d}^{*}}{d t}+\frac{L_{m}}{\tau_{r}} i_{s d}^{*}+\frac{1}{\tau_{r}} \psi_{r d}+k_{\psi}^{\prime}\left(\psi_{r d}^{*}-\psi_{r d}\right)\right]
\end{aligned}
$$

where: $k_{t}=\frac{3}{2} n_{p} \frac{\delta \sigma L_{s}}{J}, k_{\omega}, k_{\Psi}$ are positive design constants that determine the closed-loop dynamics. To $\mathrm{V}^{\prime}<0$, the stabilizing virtual controls are chosen as

$$
\begin{aligned}
& i_{s q}^{*}=\frac{1}{k_{t} \psi_{r d}}\left\lfloor k_{\omega} \varepsilon_{\omega}+\frac{d \omega_{r}^{*}}{d t}+\frac{T_{l}}{J}+B \omega_{r}+k_{\omega}^{\prime}\left(\omega_{r}^{*}-\omega_{r}\right)\right] \\
& i_{s d}^{*}=\frac{\tau_{r}}{L_{m}}\left[k_{\psi} \varepsilon_{\psi}+\frac{d \psi_{r d}^{*}}{d t}+\frac{1}{\tau_{r}} \psi_{r d}+k_{\psi}^{\prime}\left(\psi_{r d}^{*}-\psi_{r d}\right)\right]
\end{aligned}
$$


We obtain:

$$
\frac{d V_{(\omega, \psi)}}{d t}=-k_{\omega} \varepsilon_{\omega}^{2}-k_{\psi} \varepsilon_{\psi}^{2}<0
$$

\section{2 The inner current loop controllers using SM}

In this paper, the inner current control objective is to make the measured stator currents is reach the desired currents value is*. SMC is adopted for the currents loop of SPIM drives, a adaptation law for this SMC scheme is derived based on Lyapunov theory to ensure stability and fast error dynamics.

Defining the current tracking errors as:

$\varepsilon_{i_{s d}}=i_{s d}^{*}-i_{s d} ; \varepsilon_{i_{s q}}=i_{s q}^{*}-i_{s q}$

Consider s1 and s2 are the two sliding surfaces are defined for isd and isq, respectively. These sliding surfaces can be described as

$s_{1=} \varepsilon_{i_{s d}}+k_{1} \int_{0}^{t} \varepsilon_{i_{s d}} d t$
$s_{2=} \varepsilon_{i q}+k_{2} \int_{0}^{t} \varepsilon_{i_{s q}} d t$

where $\mathrm{k} 1$ and $\mathrm{k} 2$ are the undetermined coefficient. The time derivative of Lyapunov function yields:

$$
\begin{aligned}
& \dot{s}_{1}=\dot{\varepsilon}_{i_{s d}}+k_{1} \varepsilon_{i_{s d}} \\
& \dot{s}_{2}=\dot{\varepsilon}_{i q}+k_{2} \varepsilon_{i_{s q}}
\end{aligned}
$$

Substituting Equation (5) to Equation (19) and combinating to the sliding mode exponential approach law, we get the following equation:

$$
\begin{aligned}
& \dot{s}_{1}=\dot{\varepsilon}_{i_{d d}}+k_{1} \varepsilon_{i_{d d}}=i_{s d}^{*}+\frac{1}{L_{s}}\left[a i_{s d}-L_{s} \omega_{s s} i_{s q}-b R_{r} \psi_{r d}-c u_{s d}\right]+k_{1} \varepsilon_{i_{i d d}}=u_{s 1} \\
& \dot{s}_{2}=\dot{\varepsilon}_{i q}+k_{2} \varepsilon_{i_{q q}}=i_{s q}^{*}+\frac{1}{L_{s}}\left[a i_{s q}-L_{s} \omega_{s s} i_{s d}-b_{r} \omega_{r} \psi_{r d}-c u_{s o}\right]+k_{2} \varepsilon_{i_{i q}}=u_{s 2}
\end{aligned}
$$

The second order sliding controller which was proposed:

$$
\left\{\begin{array}{l}
u_{s_{1}}=-\left\lfloor\alpha_{1} \operatorname{sign}\left(s_{1}\right)+\beta_{1} \operatorname{sign}\left(p s_{1}\right)\right\rfloor \\
u_{s_{2}}=-\left[\alpha_{2} \operatorname{sign}\left(s_{2}\right)+\beta_{2} \operatorname{sign}\left(p s_{2}\right)\right]
\end{array}\right.
$$

where, $\alpha 1, \alpha 2, \beta 1, \beta 2$ are positive constants with: $\left\{\begin{array}{l}\alpha_{1}>\beta_{1}>0 \\ \alpha_{2}>\beta_{2}>0\end{array}\right.$. The sign(s) function is defined as:

$$
\operatorname{sign}\left(s_{i}\right)=\left\{\begin{array}{ccc}
-1 & \text { if } & s_{i}<0 \\
0 & \text { if } & s_{i}=0 \\
+1 & \text { if } & s_{i}>0
\end{array}\right\} \quad \text { with } i=1 ; 2
$$

The SM control law can be found using Lyapunov theory and defining the Lyapunov function candidate:
$V=\frac{1}{2}\left(\mathrm{~s}_{1}^{2}+s_{2}^{2}\right)$

The time derivative of Lyapunov function can be calculated as:

$$
\dot{V}=s_{1} s_{1}+s_{2} \dot{s}_{2}
$$

According to Lyapunov theory, if the function $\dot{V}$ is negative definite, this will ensure that the state trajectory will be driven and attracted toward the sliding surface s and once reached, it will remain sliding on it until the origin is reached asymptotically.

$$
\begin{gathered}
u_{s d}=\frac{L_{s}}{c}\left[\alpha_{1} \operatorname{sign}\left(s_{1}\right)+\beta_{1} \operatorname{sign}\left(p s_{1}\right)+p i_{s d}^{*}\right. \\
\left.+\frac{1}{L_{s}}\left(a i_{s d}-L_{s} \omega_{s} i_{s q}-b R_{r} \psi_{r d}\right)+k_{1} \varepsilon_{i s d}\right] \\
u_{s q}=\frac{L_{s}}{c}\left[\alpha_{2} \operatorname{sign}\left(s_{2}\right)+\beta_{2} \operatorname{sign}\left(p s_{2}\right)+p i_{s q}^{*}\right. \\
\left.+\frac{1}{L_{s}}\left(a i_{s q}-L_{s} \omega_{s} i_{s d}-b \omega_{r} \psi_{r d}\right)+k_{2} \varepsilon_{i s q}\right]
\end{gathered}
$$

This ensure that:

$$
\begin{aligned}
\dot{V}=- & {\left[\alpha_{1} \operatorname{sign}\left(s_{1}\right)+\beta_{1} \operatorname{sign}\left(p s_{1}\right)\right]\left[s_{1}\right] } \\
& -\left[\alpha_{2} \operatorname{sign}\left(s_{2}\right)+\beta_{2} \operatorname{sign}\left(p s_{2}\right)\right]\left[s_{2}\right]<0
\end{aligned}
$$

\subsection{Structure of the VM_SC_ MRAS Speed Observer}

In this scheme, the measured stator current components are also used as the reference model of the MRAS observer to avoid the use of a pure integrator and reduce influence of motor parameter variation as in [25]. The adaptive model is a twolayer linear $\mathrm{NN}$ to estimate the stator current has been trained online by means of a least-squares algorithm. In this VM_SC_MRAS observer proposed, the adaptive model based on the ADALINE has been improved, A linear least-square algorithm, which is more suitable than a nonlinear one, like the BPN, is used to reduce the computation effort and overcome some drawbacks, which cause by its inherent nonlinearity. Furthermore, the employment of the adaptive model in prediction mode leads to a quicker convergence of the algorithm, a higher bandwidth of the speed control loop, a better behavior at zero-speed, lower speed estimation errors both in transient and steady state conditions.

Rearranging (26), the matrix equation is obtained in prediction mode; see (28). This matrix equation can be solved by any least square technique.(Eq. 32) 


$$
\begin{aligned}
& \hat{i}_{s D}(k)=w_{1} i_{s D}(k-1)+w_{2} u_{s D}(k-1)+w_{3} \hat{\psi}_{r d}(k-1)+w_{4} \hat{\psi}_{r q}(k-1)+w_{5} i_{s D}(k-2)-w_{6} u_{s D}(k-2) \\
& \hat{i}_{s Q}(k)=w_{1} i_{s Q}(k-1)+w_{2} u_{s Q}(k-1)+w_{3} \hat{\psi}_{r q}(k-1)-w_{4} \hat{\psi}_{r d}(k-1)+w_{5} i_{s Q}(k-2)-w_{6} u_{s Q}(k-2) \\
& -w_{7} \hat{\psi}_{r D}(k-2)-w_{8} \hat{\psi}_{r Q}(k-2) \\
& -w_{7} \hat{\psi}_{r Q}(k-2)+w_{8} \hat{\psi}_{r D}(k-2) \\
& w_{1}=1-\frac{3 T R_{s}}{2 \sigma L_{s}}-\frac{3 T L_{m}^{2}}{2 \sigma L_{r} L_{s} T_{r}} ; w_{2}=\frac{3 T}{2 \sigma L_{s}} ; w_{3}=\frac{3 T L_{m}}{2 \sigma L_{r} L_{s} T_{r}} ; w_{4}=\frac{3 T L_{m}}{2 \sigma L_{r} L_{s}} \omega_{r} ; w_{5}=\frac{3 T R_{s}}{2 \sigma L_{s}}+\frac{T L_{m}^{2}}{2 \sigma L_{r} L_{s} T_{r}} ; w_{6}=\frac{T}{2 \sigma L_{s}} ;
\end{aligned}
$$

Matrix equation (26) can be written as (28), This is a classical matrix equation of the type, where $\mathrm{A}$ is called a "data matrix", b is called an "observation vector," and $\omega r$ is the scalar unknown. In this application a classical LS algorithm in a recursive form has been employed. This algorithm is described in detail in [26]. Fig. 5 shows the block diagram of the VM_SC_MRAS speed observer. In this paper, authors focus on analysing OLS algorithm.

\subsubsection{Rotor Speed Estimation Algorithm:}

$\mathrm{Ax} \sim \mathrm{b}$ is the linear regression problem under hand. All LS problems have been generalized by using a parameterized formulation (generalized LS) of an error function whose minimization yields the corresponding solution. This error is given by:

$$
E_{L S}=\frac{(A x-b)^{T}(A x-b)}{1-\xi+\xi X^{T} X}
$$

where $\mathrm{T}$ represents the transpose and $\xi$ is equal to 0.5 for TLS, 1 for DLS and 0 for OLS.

Using OLS algorithm, this error is given by:

$$
E_{O L S}=(A x-b)^{T}(A x-b)
$$

where:

$$
(A x-b)=\varepsilon=\left[\begin{array}{c}
\varepsilon_{i s D} \\
\varepsilon_{i s Q}
\end{array}\right]=\left[\begin{array}{c}
i_{s D}(\mathrm{k})-\hat{i}_{s D}(\mathrm{k}) \\
i_{s Q}(\mathrm{k})-\hat{i}_{s Q}(\mathrm{k})
\end{array} .\right.
$$

This error can be minimized with a gradient descent method:

$$
\omega_{r}(\mathrm{k}+1)=\omega_{r}(\mathrm{k})-\eta \gamma(\mathrm{k}) \mathrm{a}(\mathrm{k})
$$

where $\quad \gamma(k)=a(k)^{T} a(k)-b(k)$

with $\eta$ is the learning rate, $\mathrm{a}(\mathrm{k})$ is the row of $\mathrm{A}$ fed at instant $\mathrm{k}$, and $\mathrm{b}(\mathrm{k})$ is the corresponding observation.

\subsubsection{Rotor Flux identifier and stability analysis}

In this proposed control scheme, the rotor flux values were generated base on equation VM.

$$
\begin{aligned}
& \frac{d \hat{\psi}_{r d}}{d t}=\frac{L_{r}}{L_{m}}\left(u_{s D}-R_{s} i_{s D}-\sigma L_{s} \frac{d i_{s D}}{d t}\right) ; \\
& \frac{d \hat{\psi}_{r q}}{d t}=\frac{L_{r}}{L_{m}}\left(u_{s Q}-R_{s} i_{s Q}-\sigma L_{s} \frac{d i_{s Q}}{d t}\right) ;
\end{aligned}
$$

These rotor flux components are identified based on the control voltage and the measured stator current components. Using this VM to identify rotor flux will overcome the instability problem in the regenerating mode of operation, what appear using $\mathrm{CM}$ rotor flux identifier.

In the proposed LS based adaptive speed observer the online $\mathrm{R}_{\mathrm{s}}$ estimation methodologies proposed in [46] have been used, summarized in the following. In particular Rs is estimated on the basis of the $i_{s D}, i_{s D}$ measured and $\hat{i}_{s D}, \hat{i}_{s Q}$ estimated stator current components, by means of the following update law:

$$
\frac{d R_{s}}{d t}=-\mu\left(\left(i_{s D}-\hat{i}_{s D}\right) \hat{i}_{s D}+\left(i_{s Q}-\hat{i}_{s Q}\right) \hat{i}_{s Q}\right)
$$

where $\mu$ is a properly chosen positive constant. $R r$ has been estimated based on its variation proportional to that one of the Rs on the basis of the following law:

$\hat{R}_{r}=K_{r} \hat{R}_{s}$

where $\mathrm{Kr}$ is the ratio of the rated values of the stator and rotor resistances. The estimated resistance values were update for the current observer to estimate the current exactly more.

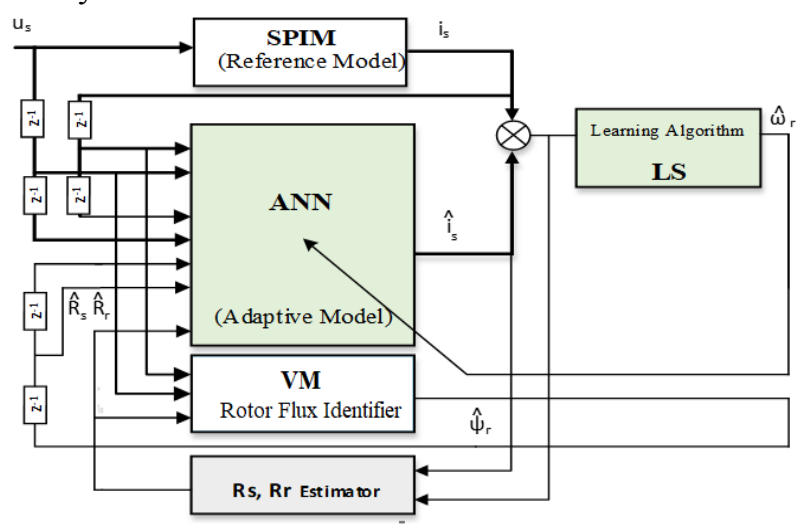

Fig 5 VM_SC_MRAS speed observer

\section{Simulink and discussion}


To confirm the quality of the SPIM sensorless control system for the ship propulsion system, the simulations were performed in this section. Simulation model was established by Matlab / Simulink tool. The simulations were performed based on the surveys conducted for the ship propulsion system in [24], [27], [28].
SPIM parameters: $1 \mathrm{HP}, 220 \mathrm{~V}, 50 \mathrm{~Hz}, 4$ pole, $1450 \mathrm{rpm} . \mathrm{Rs}=10.1 \Omega, \mathrm{Rr}=9.8546 \Omega, \mathrm{Ls}=$ $0.833457 \mathrm{H}, \mathrm{Lr}=0.830811 \mathrm{H}, \mathrm{Lm}=0.783106 \mathrm{H}, \mathrm{Ji}$ $=0.0088 \mathrm{~kg} \cdot \mathrm{m} 2$. Rs is nominal value of stator resistance.

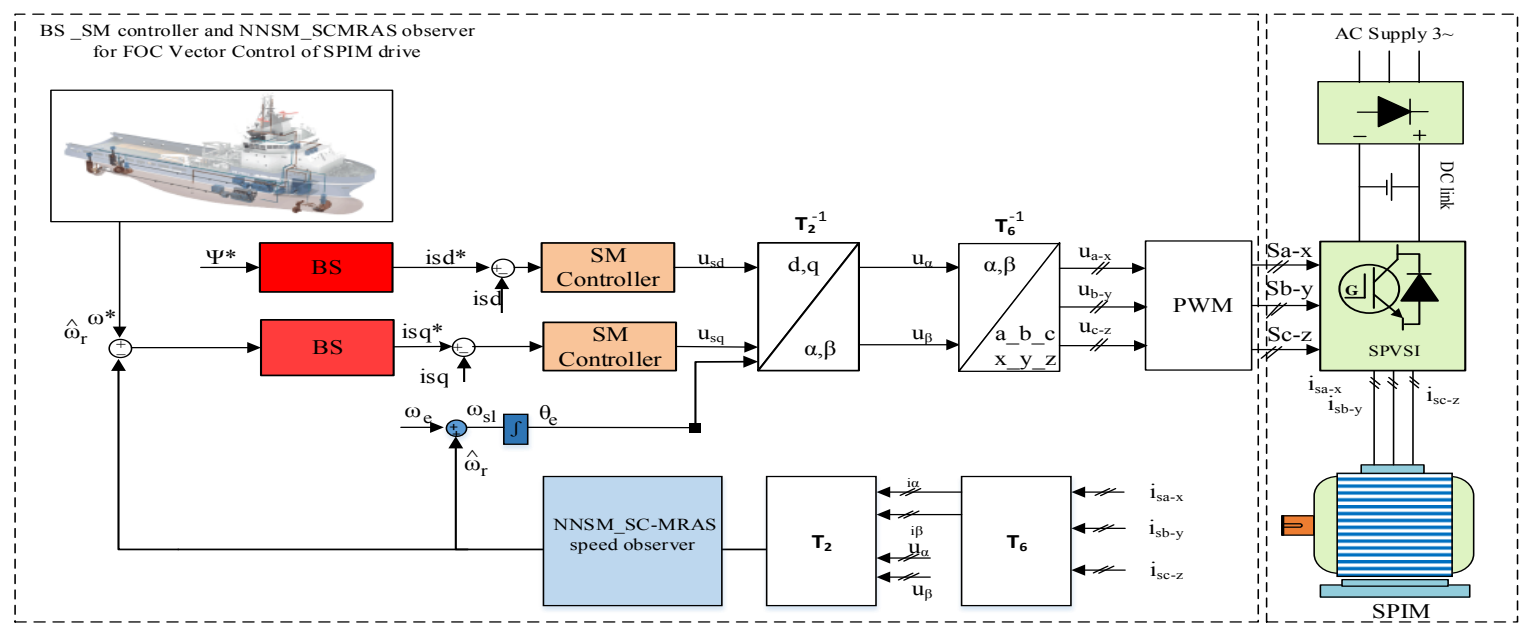

Fig. 4 Vector control of SPIM drive using RBF based on PI_SM control structure

\section{1 first case:}

In the free running ship velocity survey conducted based on [24, Figure 4-6], to evaluate the controller quality and estimate of the BS_SM method that combines VM_SCMRAS in the low and zero speed range, the low speed reference step from initial value of $100 \mathrm{rpm}$ down to $5 \mathrm{rpm}$. As observed in Figure $6 \mathrm{a}$, it is easy to see that the actual speed of the SPIM closely follows the reference speed, the estimated error and the speed tracking error are very small and nearly zero in both the established and transient mode as Fig.6b. The instant torque response according to load torque requirement $6 \mathrm{c}$. The motor stator current shown in Figure 6d shows a good sine wave in a six-phase static reference
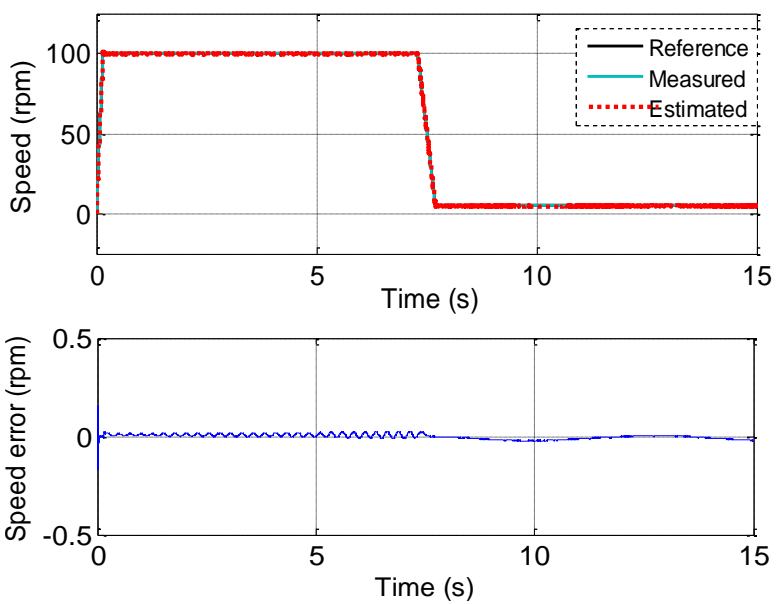

frame. The is $\alpha \beta$ current response in the corresponding stator reference frame also indicates that the is $\alpha$ current is well controlled and kept stable throughout the survey to provide the rotor flux value following the reference flux. The quality of the sensorless control system is confirmed at a very low speed range of $5 \mathrm{rpm}$. In this speed range the observer still works very accurately, the estimated speed is very close to the set speed, the estimated error does not change and is close to zero. The controller also controls the speed and torque well within this speed range, the actual speed of the motor closely following the reference speed.
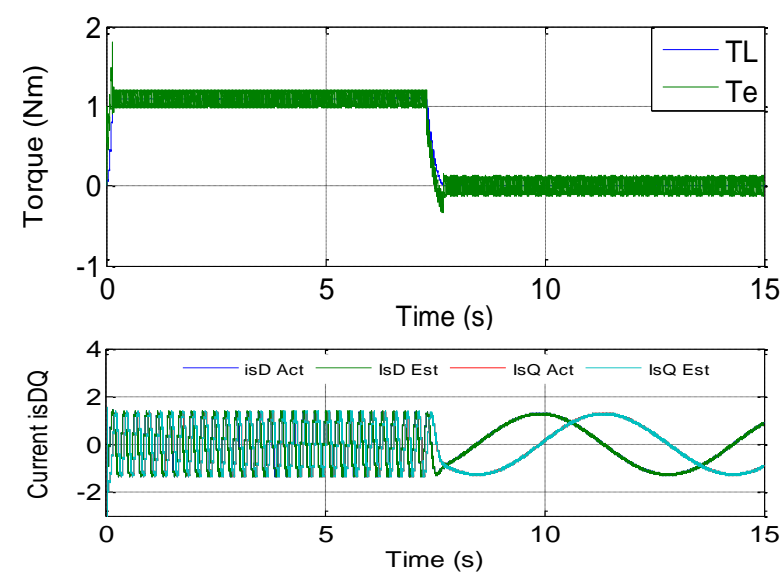

Fig. 6 Torque, stator current, speed response, estimated error in case of speed change : $100 \mathrm{rpm}-5 \mathrm{rpm}$, [[24, Figure 4-6] 
Another case with the speed reference being accelerated from the initial $50 \mathrm{rpm}$ to $100 \mathrm{rpm}$ also was surveyed according to [27, Figure 9]. Figure 7 shows the torque, stator current, speed response in case the speed changes in the speed range: $50 \mathrm{rpm}$ $100 \mathrm{rpm}$. Observing the simulation results can see that, when the reference speed is changed, BS_SM and VM_SCMRAS work effectively. The speed control and estimation quality are very good. The electromagnetic torque of SPIM and the load torque of the propeller, the actual Isdq current and the estimated current in Figure 6 show that the current and the torque are response fast, instantaneous.

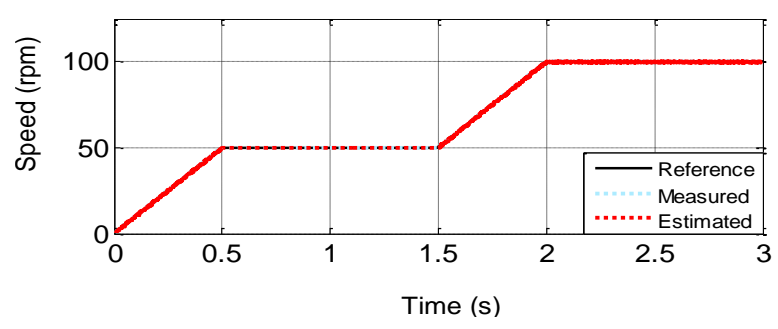

Fig. 7 Torque, stator current, speed response, estimated error in case of speed change : $50 \mathrm{rpm}$ $100 \mathrm{rpm}$, [27, Figure 9]

\section{2. Case 2}

The various tests have been carried out based on emergency stops during incidents in [28]. This is an emergency that stops the ship as quickly as possible. To simulate it, the speed reference set up speed reversal with the torque is applied. The survey was carried out at low speed range. Fig. 7 shows the torque, stator current, speed response, estimated
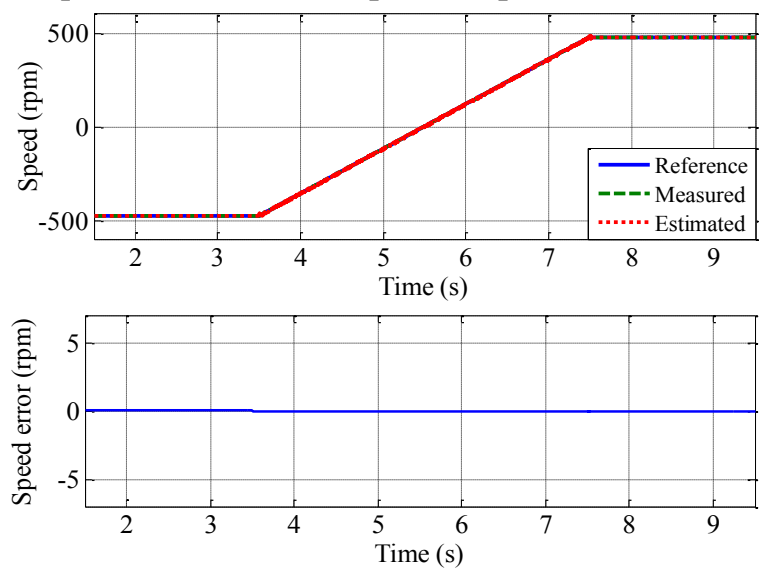

Fig. 8 Torque, stator current, speed response, estimated error in case of cash_stop without load $+/-500$

rpm. [26, Hình 7].

From the results obtained in Figure 6 and Figure 7, we can see that the BS_SM controller works effectively, controlling speed and torque well. The propeller speed can accurately track the reference speed, instantaneous current and torque response in both in transient and steady state conditions. The survey results also show that the VM_SCMRAS observation works well even when the propeller rotates at a very low speed $(5 \mathrm{rpm})$. Estimated errors and small speed tracking errors approach zero in the two survey cases.
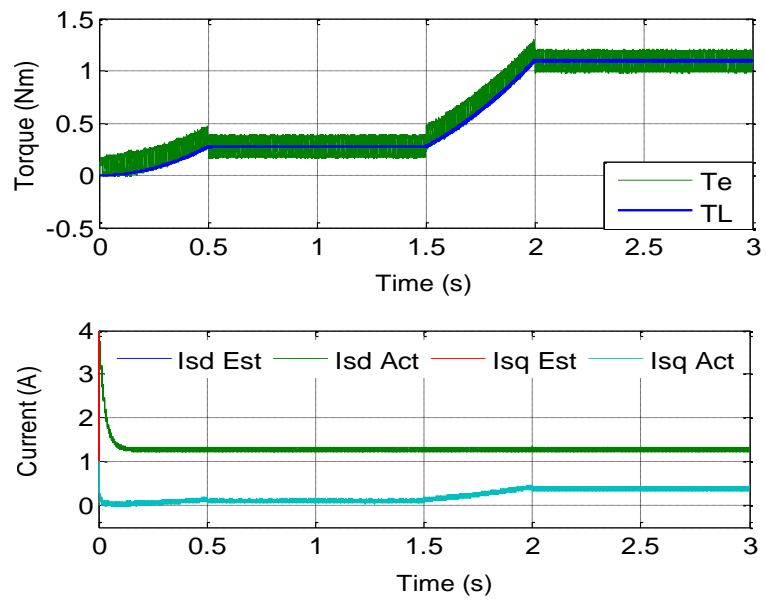

error, in cash stop condition (control stopping trouble) with operating speed $+-500 \mathrm{rpm}$, no-load according to [28, figure 7]. Figure 9 Torque, current, speed response, estimated error, in case of cash_stop (control when stopping the problem) operating speed at $+/-350 \mathrm{rpm}, 37.5 \%$ of rated load according to [28, Figure 9].
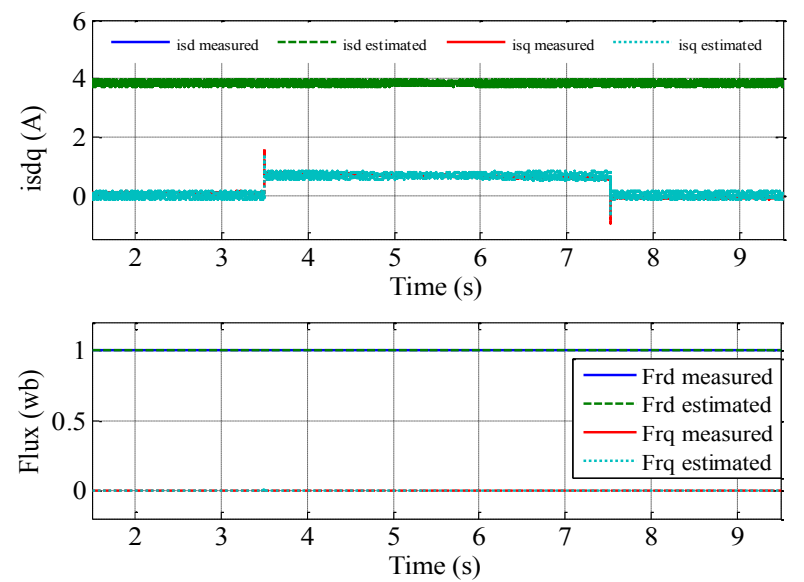

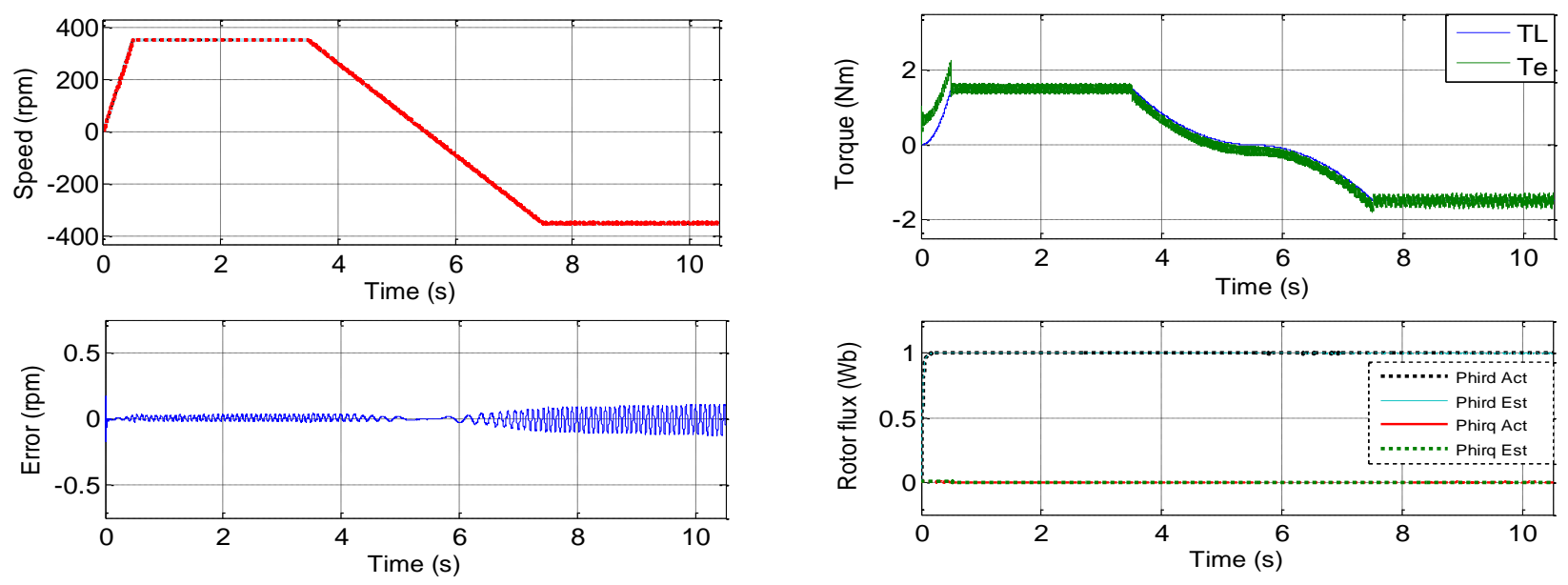

Fig. 9 Torque, stator current, speed response, estimated error in case of cash_stop at $+/-350 \mathrm{rpm}, 37.5 \%$ of rated load according to [28, Figure 9]

Figure 10 Torque, current, speed response, estimated error, in cash_stop condition at speeds lower than $+-50 \mathrm{rpm}, 12 \%$ of rated load according to [24, Figure-6]. The simulation test results of the ship propulsion system are shown in Figure 10. The stator current shown in Figure 10d shows a good sine wave in a six-phase static reference frame. The isdq current response in the corresponding rotating
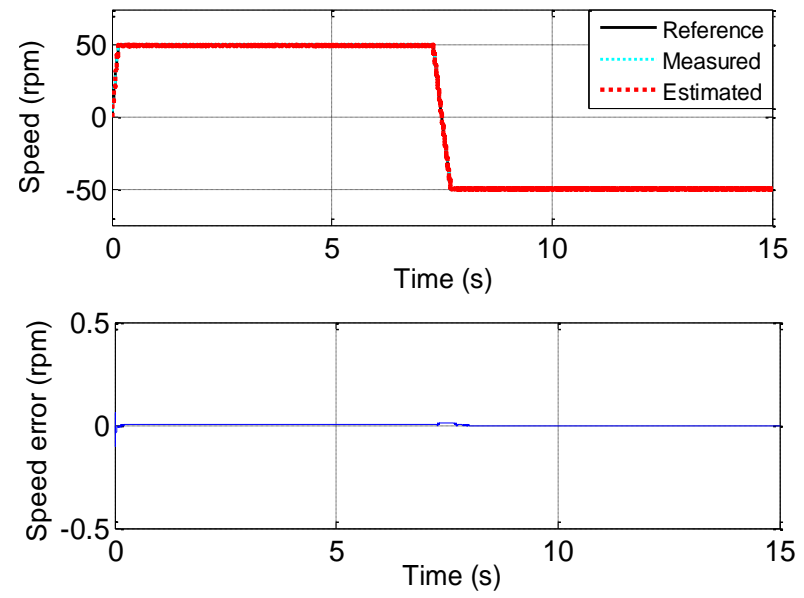

reference frame shows that the isq line responds quickly and completely to the required torque, the isd line is well controlled and kept stable throughout the survey to provide rotor flux value follow the reference flux. When the SPIM is reversed, isdq still tracks and follows the reference isdq very well, for fast and robust response. SPIM works well at low speeds in both forward and reverse rotation.
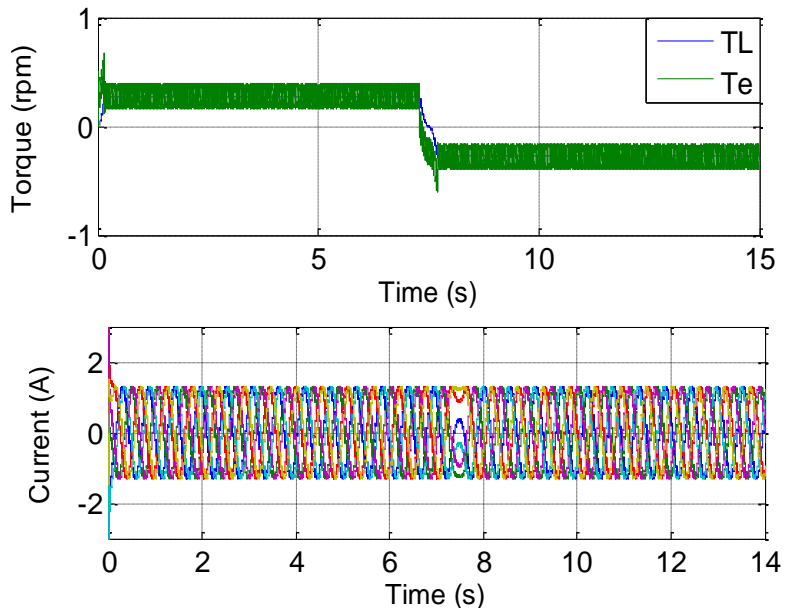

Fig. 10 Torque, stator current, speed response, estimated error in case of cash_stop at $+/-50 \mathrm{rpm}, 12 \%$ of rated load according to [24, Figure 6]

Tests through simulation been performed showed that the proposed scheme has provided high quality controllers and estimator for electric propulsion of ship. In results in Fig. 6- Fig. 10 proved that the rotor speed has been accurately estimated at both very low speed (5 rpm) and when the motor is reversed. Maximum estimation error is less than $2 \mathrm{rpm}$. The sumulation results shown in Fig. 6- Fig. 10 also demonstrate that the vector control of SPIM for propulsion systems using the new nonlinear control structure works very well and correctly. The sensorless vector control drive system of SPIM drives been proposed works with high accurate, reliably, stably and robustness.

\section{Conclusion}

In the paper, the proposed sensorless strategy has made the ship's electric propulsion system having smaller structure and higher reliability, accuracy operation system. The electric propulsion systems in ships require a wide range of working speed, especially at low speed ranges. The VM_SCMRAS adaptive speed observer and the BS_SM controller meets the requirements of ship propulsion systems because it can accurately estimate and control SPIM's thrust even at zero and low speed regions and. From the research results it has been confirmed that sensorless control using 
BS_SM and the VM_SCMRAS speed estimator provides accurate control and estimation signals for propulsion systems. In fact, the performance of the ship is greatly influenced by the quality of the propulsion motor drive control system, the application of modern control techniques to improve the efficiency of this ship propulsion have high practical significance.

\section{REFERENCES:}

[1] C. C. Chan et al., "Electric vehicles charge forward," IEEE Power Energy Mag, Vol. 2, pp. 24-33, 2004.

[2] V. Erginer, M. H. Sarul, "High Performance and Reliable Torque Control of Permanent Magnet Synchronous Motors in Electric Vehicle Applications", Elektronika ir Elektrotechnika, Vol. 19, pp. 41-46, 2013.

[3] I. Husain, "Electric and hybrid vehicles: design fundamentals", CRC press, 2011.

[4] C. C. Chan, "The state of the art of electric and hybrid vehicles," Proc. IEEE, Vol. 90, pp. 247-275, 2002.

[5] A. Haddoun1,2, M.E.H. Benbouzid1, D. Diallo3, R. Abdessemed4, J. Ghouili5 and K. Srairi "Comparative Analysis of Estimation Techniques of SFOC Induction Motor for Electric Vehicles", Proceedings of the 2008 International Conference on Electrical Machines, Oct, 2018.

[6] S. Woosuk, S. Jincheol, and J. Yu-seok, "EnergyEfficient and Robust Control for High-Performance Induction Motor Drive With an Application in Electric Vehicles," IEEE Transactions on Vehicular Technology, Vol. 61, pp. 3394-3405, 2012.

[7] Farid Khoucha, Khoudir Marouani, Abdelaziz Kheloui, Mohamed Benbouzid. "A Sensorless Direct Torque Control Scheme Suitable for Electric Vehicles," Electromotion, Vol. 16, pp.89-97, 2009.

[8] J. W. Finch and D. Giaouris, "Controlled AC electrical drives," IEEE Trans. Ind. Electron, Vol. 55, pp. 481-491., Feb. 2008.

[9] W. Leonhard, Control of Electrical Drives: Springer, 2001.

[10] Hamou Ait Abbasa, Mohammed Belkheirib, Boubakeur Zegninia, Feedback Linearization Control of An Induction Machine Augmented by Single Hidden Layer Neural Networks, International Journal of Control, Vol. 89, pp.140-155, 2015.

[11] Yassine Kali, Magno Ayala 2, Jorge Rodas 2 , Maarouf Saad 1 , Jesus Doval-Gandoy 3, Raul Gregor 2 and Khalid Benjelloun 4, "Current Control of a Six-Phase Induction Machine Drive Based on Discrete-Time Sliding Mode with Time Delay Estimation" Energies, Vol. 12, 2019.

[12] Mehazzem F, Nemmour AL, Reama A, Benalla H. "Nonlinear integral backstepping control for induction motors". In: Proceedings of 2011 International Aegean Conference on Electrical Machines and Power Electronics and Electromotion, Joint Conference, Istanbul, Turkey, 2011.
[13] M.R Jovanovic, B. Bamieh, "Architecture Induced by Distributed Backstepping Design", IEEE Transactions on Automatic Control, Vol. 52, pp. 108 - 113, Jan 2007.

[14] Yassine Kali, Magno Ayala 2, Jorge Rodas 2, Maarouf Saad 1 , Jesus Doval-Gandoy 3, Raul Gregor 2 and Khalid Benjelloun 4, "Current Control of a Six-Phase Induction Machine Drive Based on Discrete-Time Sliding Mode with Time Delay Estimation" Energies, 12(1) , 2019.

[15] Nasir Uddin M. Huang Z. R.; Siddique Hossain A. B. M., "Development and Implementation of a Simplified Self-Tuned Neuro-FuzzyBased IM Drive". IEEE Transactions on Industry Applications, Vol. 50 (1), 51-59, 2014.

[16] I. Gonzalez-Prieto, M.J. Duran, J.J. Aciego, C. Martin, F. Barrero, "Model Predictive Control of Six-phase Induction Motor Drives Using Virtual Voltage Vectors" IEEE Transactions on Industrial Electronics, Vol. 65(1), 2018.

[17] Zhiping Cheng, Liucheng Jiao, Hamiltoniaian Modeling and Passivity-based Control of Permanent Magnet Linear Synchronous Motor, Journal Of Computers, Vol. 26, pp. 501-508, February 2013.

[18] Abderrahmen Zaafouri, Chiheb Ben Regaya, Hechmi Ben Azza, Abdelkader Châari, "zDSP-based adaptive backstepping using the tracking errors for high-performance sensorless speed control of induction motor drive", ISA Transactions, Vol. 60, pp. 333-347, 2016.

[19] Q. Su, W. Quan, G. Cai, et al., Improved adaptive backstepping sliding mode control for generator steam valves of non-linear power systems, IET Control Theory Appl., 2017, Vol. 11 , pp. 1414-1419.

[20] 20Z. Liu, B. Chen, C. Lin, Adaptive neural backstepping for a class of switched nonlinear system without strict-feedback form, IEEE Trans. Syst. Man Cybern. Syst., 2017, Vol. 47 , pp.13151320.

[21] H. Li, L. Wang, H. Du, et al., Adaptive fuzzy backstepping tracking control for strict-feedback systems with input delay, IEEE Trans. Fuzzy Syst., 2017, Vol. 25 , pp. 642-652.

[22] Flah A, Novak M, Lassaad S. An Improved Reactive Power MRAS Speed Estimator With Optimization for a Hybrid Electric Vehicles Application. J. Dyn. Syst. Meas. Control., 2018, Vol. 140, pp.061 016.

[23] E. Levi, Multiphase electric machines for variable-speed applications, IEEE Transactions on Industrial Electronics. , 2008, Vol 55, pp. 1893 1909.

[24] Zhixiong Li, Xinping Yan and Zhongxiao Peng, "Ship electric propulsion with a sensorless permanent magnet synchronous motor: A simulation study", Journal Engineering for the Maritime Environment, Vol. 226, No.4, 2015. 
[25] Cirrincione G, Cirrincione M, Hérault J, Van Huffel S. The MCA EXIN neuron for the minor component analysis: Fundamentals and comparisons. IEEE Trans. Neural Netw., 2002, Vol. 13, pp. 160 187.

[26] Ngoc Thuy Pham, Khuong Huu Nguyen, "Sensorless Control for High Performance SPIM Drives Based on the Improved Rotor Flux Identifier Using Sliding Mode" International Journal of Intelligent Engineering and Systems (ISSN: $2185-$ 3118), Aug 2019, Volume 12, No.4, pp. 291-305.

[27] [26] [173]1.Jun-Jie Ren, Yan-Cheng Liu, Ning Wang, Si-Yuan Liu, "Sensorless control of ship propulsion interior permanent magnet synchronous motor based on a new sliding mode observer", ISA Transactions, Vol ,No. , 2014.

[28] F. Temen, S. Siala and P. Noy "Multiphase Induction Motor Sensorless Control For Electric Ship Propulsion" Second International Conference on Power Electronics, Machines and Drives (PEMD 2004), pp. 556-561.

\section{Creative Commons Attribution License 4.0 (Attribution 4.0 International, CC BY 4.0)}

This article is published under the terms of the Creative Commons Attribution License 4.0

https://creativecommons.org/licenses/by/4.0/deed.en US 